\title{
DÜBLIN
}

Technological University Dublin ARROW@TU Dublin

2020-02-25

\section{Millimetre-wave Planar Bruce Array Antenna}

\author{
Zeeshan Ahmed \\ Technological University Dublin \\ Manh ha Hoang \\ Technological University Dublin \\ Patrick McEvoy \\ Technological University Dublin, patrick.mcevoy@tudublin.ie
}

See next page for additional authors

Follow this and additional works at: https://arrow.tudublin.ie/engineduccon

Part of the Electrical and Computer Engineering Commons, and the Other Engineering Commons

\section{Recommended Citation}

Z. Ahmed, M. H. Hoang, P. McEvoy and M. J. Ammann. (2020). Millimetre-wave Planar Bruce Array Antenna. 2020 International Workshop on Antenna Technology (iWAT), Bucharest, Romania, 2020, pp. 1-3. doi: 10.1109/iWAT48004.2020.1570608201.

This Article is brought to you for free and open access by the Engineering: Education and Innovation at ARROW@TU Dublin. It has been accepted for inclusion in Conference papers by an authorized administrator of ARROW@TU Dublin. For more information, please contact arrow.admin@tudublin.ie, aisling.coyne@tudublin.ie, gerard.connolly@tudublin.ie. Funder: Science Foundation Ireland 
Authors

Zeeshan Ahmed, Manh ha Hoang, Patrick McEvoy, and Max Ammann

This article is available at ARROW@TU Dublin: https://arrow.tudublin.ie/engineduccon/32 


\title{
Millimetre-wave Planar Bruce Array Antenna
}

\author{
Zeeshan Ahmed ${ }^{1,2 *}$, Manh Ha Hoang ${ }^{1,2}$, Patrick McEvoy ${ }^{1}$, Max J. Ammann ${ }^{1,2}$ \\ ${ }^{I}$ Antenna and High-Frequency Research Centre, School of Electrical \& Electronic Engineering, \\ Technological University Dublin, Dublin, Ireland \\ ${ }^{2}$ CONNECT - Ireland's Research Centre for Future Networks and Communications, Dublin, Ireland \\ *d16127520@mytudublin.ie
}

\begin{abstract}
A tri-band mm-wave planar Bruce array antenna for fifth generation communications (5G) is presented. The 16-element planar Bruce array antenna is simulated and fabricated on Rogers RT/Duroid 5880 substrate with thickness of $0.254 \mathrm{~mm}$. For a compact and simple structure, the antenna has a highly directional fan-beam radiation pattern at broadside and peak realized gain of $14.0 \mathrm{dBi}$.
\end{abstract}

Keywords- meandered structure, antenna array, $5 G, \mathrm{~mm}$ wave, fan beam radiation pattern

\section{INTRODUCTION}

In 1927, Edmond Bruce proposed a meander line wire Bruce array antenna (BAA) [1]. The antenna is capable of moderate bandwidth and gain. Although being a very simple model and around for over nine decades, it has not drawn much attention from the research community. In 1996, Nakano et al. combined the performance of Bruce and Franklin array at $12.5 \mathrm{GHz}$ [2] and most recent work on Bruce array was Chen's who designed a slot-type Bruce array antenna for 5-6 GHz band [3].

The global expansion of the wireless industry has increased the demand of low latency wireless communications. In order to develop next generation wireless communications, the scientific community has been working on quality research to accommodate more users and their demand for high data rate for which the introduction of $28 \mathrm{GHz} 5 \mathrm{G} \mathrm{mm}$-wave frequency band is a strong and suitable candidate to meet the high data rate and low latency challenges. In the quest of achieving high gain and directive radiation patterns, several recent studies have emerged which include microstrip antenna arrays [4], sub-integrated waveguide (SIW) structures [5] and stacked patch arrays [6].

In this paper, the transition from wire Bruce array antenna to planar technology is discussed. The proposed planar Bruce array antenna operates in three frequency bands with optimization focus on $28.0 \mathrm{GHz}$ band that has a directive fan-beam radiation pattern at broadside whereas the other two operating frequency ranges, i.e. $31.13 \mathrm{GHz}$ to $31.99 \mathrm{GHz}$ and $33.85 \mathrm{GHz}$ to $34.85 \mathrm{GHz}$, have dual beam radiation patterns. A grid array antenna that supports single and dual beams at different frequency bands is presented in [7]. The spacing between the vertical elements play key role in the reduction of mutual coupling between the elements to avoid unwanted radiation in the mm-wave region. The paper is divided into three parts. Section 2 covers the working principle of conventional wire Bruce array antenna and its planar equivalent. The parametric effects, impedance bandwidth, realized gain, radiation patterns and other results of the rear-fed planar geometry are discussed in section 3 .

This publication has emanated from research conducted with the financial support of Science Foundation Ireland (SFI) and is co-funded under the European Regional Development Fund under Grant Number $13 / \mathrm{RC} / 2077$

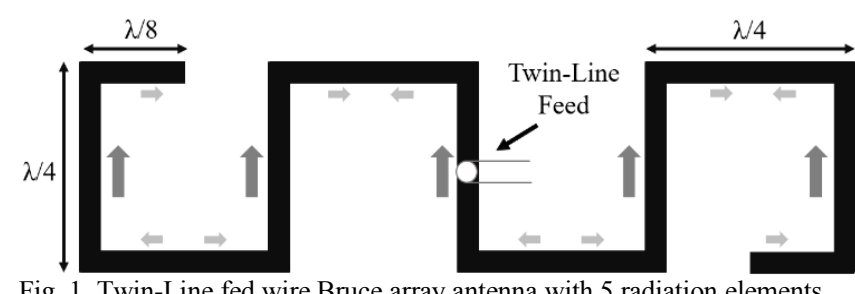

Fig. 1. Twin-Line fed wire Bruce array antenna with 5 radiation elements

\section{GeOMEtRy of BrUCE ARRAy ANTENNA}

\section{A. Review of wire Bruce Array Antenna}

The original Bruce array was created by meandering a long wire for radio ham applications. The horizontal and vertical segments of the structure are approximately quarter wavelength long and fed using a twin line feed structure as shown in Figure 1. The size of arrows indicate the intensity of the currents. The segments at the end of the structure are half of quarter wavelength in length. The vertical segments of the wire operate as radiating elements as the currents addup in broadside constructively whereas the horizontal segments are connecting elements in which the currents are out of phase therefore cancel the radiation in broadside. Meanwhile, for the inward bent end segments, the current flows in the same direction that would have cross-polarized radiation however the level of radiation remains low due to the small magnitude of current.

\section{B. Planar Bruce Array Antenna Geometry}

Figure 2(a) shows the geometry of planar Bruce array antenna with 16 radiating elements. The antenna is designed on the principles of wire Bruce array except for the horizontal and vertical lengths which are modified to $1.46 * \lambda_{\mathrm{g}} / 4$ because at $28.0 \mathrm{GHz}$, the gap between vertical

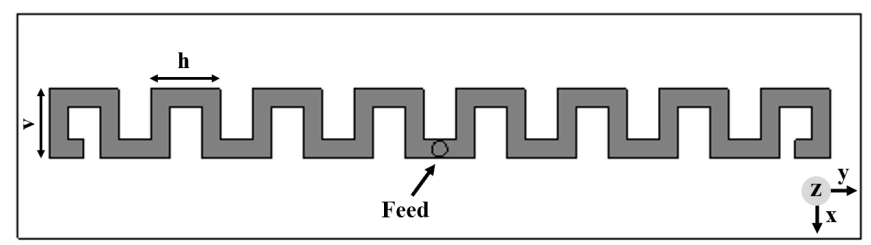

(a)

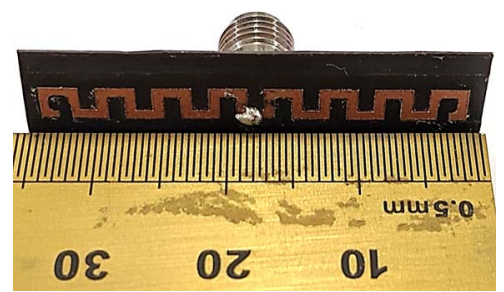

(b)

Fig. 2. (a) Geometry and (b) Prototype of co-axial fed planar Bruce array antenna with 16 elements 


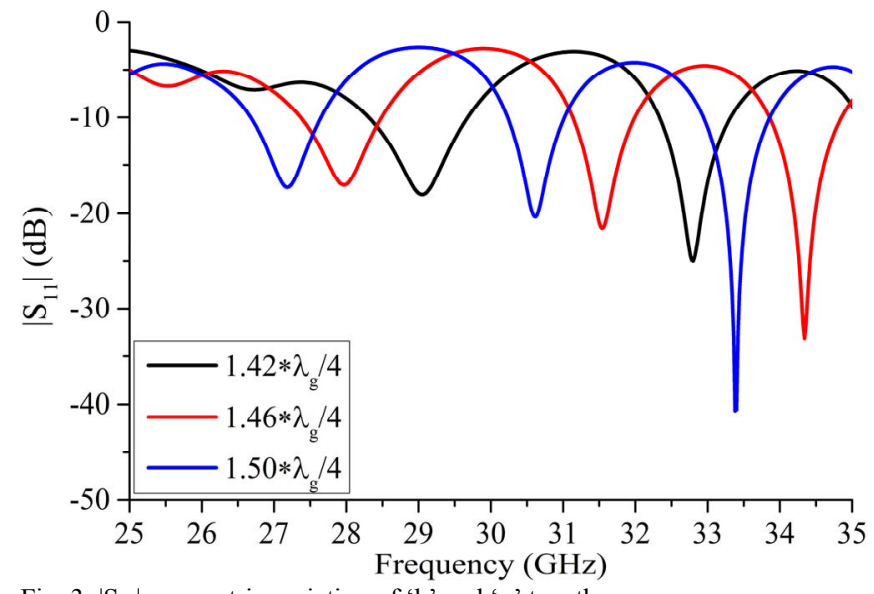

Fig. 3. $\left|\mathrm{S}_{11}\right|$ parametric variation of ' $h$ ' and ' $v$ ' together

elements ' $\mathrm{v}$ ' with $\lambda_{\mathrm{g}} / 4$ becomes so small that mutual coupling occurs between these elements. The antenna is fabricated on $35.0 \times 9.0 \mathrm{~mm}^{2}$ Rogers RT/Duroid 5880 substrate with thickness of $0.254 \mathrm{~mm}$, relative permittivity of 2.2 and dielectric loss tangent of 0.0009 with copper cladding on both sides. The antenna is fed from the bottom using $50 \Omega$ Southwest SMK 1014-33SF connector.

\section{PARAMETRIC ANALYSIS, RESUlTS AND DisCUSSION}

The effect of varying the lengths ' $v$ ' and ' $h$ ' simultaneously has been presented in Figure 3. The frequency response tunes down as the lengths increase and behaves otherwise as the lengths of radiating and interconnecting elements decrease. The variation in lengths has no considerable effect on the bandwidth of the antenna however the impedance matching improves as the lengths are decreased from $1.50 * \lambda_{\mathrm{g}} / 4$ to $1.42 * \lambda_{\mathrm{g}} / 4(2.94 \mathrm{~mm}$ to $2.78 \mathrm{~mm})$.

Figure 4 shows the measured and simulated $\left|\mathrm{S}_{11}\right|$ for the planar Bruce array antenna with ' $v$ ' and ' $h$ ' element lengths of $1.46^{*} \lambda_{\mathrm{g}} / 4(2.87 \mathrm{~mm})$ and $50 \Omega$ matched width of $0.76 \mathrm{~mm}$ throughout the structure. The antenna is measured using Rhode and Schwarz Vector Network Analyzer (ZVA40). The antenna has $\left|\mathrm{S}_{11}\right|<-10 \mathrm{~dB}$ between $27.36 \mathrm{GHz}$ to $28.50 \mathrm{GHz}, 31.13 \mathrm{GHz}$ to $31.99 \mathrm{GHz}$ and $33.85 \mathrm{GHz}$ to $34.85 \mathrm{GHz}$.

The total radiated power in all directions is defined as [8]:

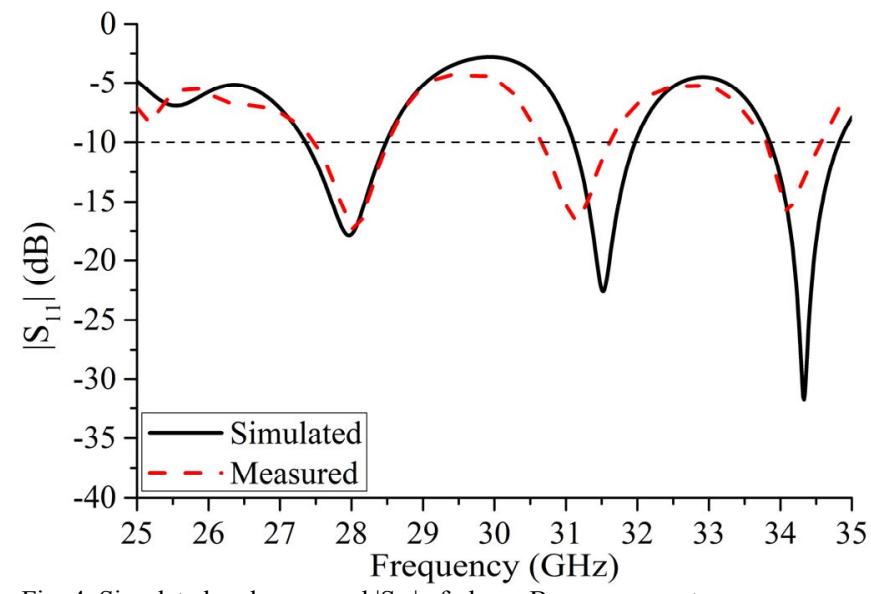

Fig. 4. Simulated and measured $\left|S_{11}\right|$ of planar Bruce array antenna

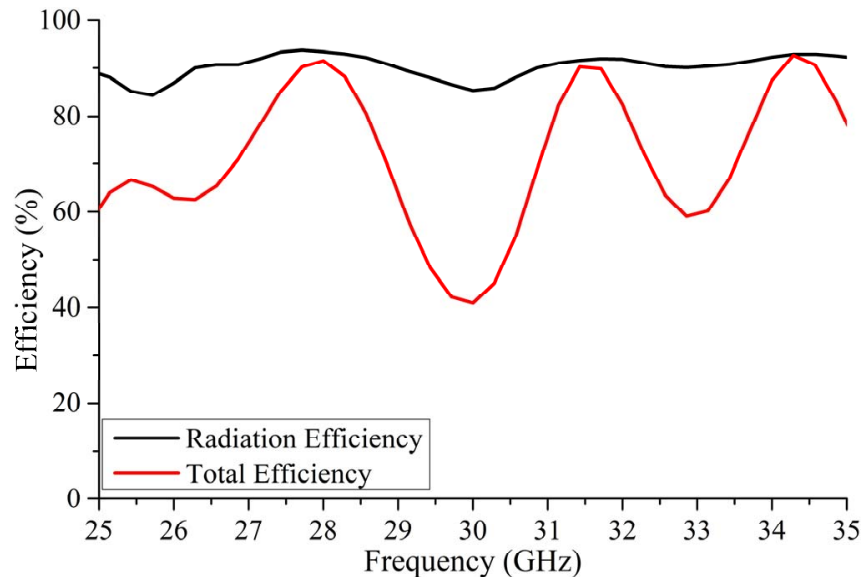

Fig. 5. Total and radiation efficiency of planar Bruce array antenna

$$
\eta=\frac{P_{r}}{P_{I N}}
$$

where $P_{r}$ is the radiated power in all directions and $\mathrm{P}_{\mathrm{IN}}$ is the input power of the antenna. The simulated radiation and total efficiencies of the antenna are shown in Figure 5. The antenna has over $85 \%$ total efficiency in the operating frequency bands and has more than $90 \%$ efficiency at 28.0 GHz, $31.50 \mathrm{GHz}$ and $34.30 \mathrm{GHz}$.

Figure 6 shows the realized gain plot of Bruce array antenna. The antenna has peak realized gain of $14.0 \mathrm{dBi}$ at $28.0 \mathrm{GHz}$ and $10.70 \mathrm{dBi}$ at both $31.54 \mathrm{GHz}$ and $34.34 \mathrm{GHz}$. In Figure 6, the gain drop in the latter two operating bands is observed because of the dual beam patterns.

The radiation pattern plots, simulated in CST Microwave Studio 2018 and measured in anechoic chamber, are presented in Figure 7. Figure 7(a) shows plot of yz-plane of the antenna. The antenna has a highly directive radiation pattern with half power beamwidth (HPBW) of $17^{\circ}$ and sidelobe level (SLL) of $-18.0 \mathrm{~dB}$, thereby verifying the fanbeam radiation pattern. Dual beam patterns are observed at $31.54 \mathrm{GHz}$ and $34.34 \mathrm{GHz}$ with peak-to-peak angular separation of $34^{\circ}$ and $62^{\circ}$, respectively, as shown in Figures 7(a) and 7(b). The antenna is symmetric to the substrate in $\mathrm{xz}$-plane but the asymmetry in the feed position in yz-plane results in pattern tilt observed at $31.54 \mathrm{GHz}$ and 34.34 GHz in Figure 7(b).

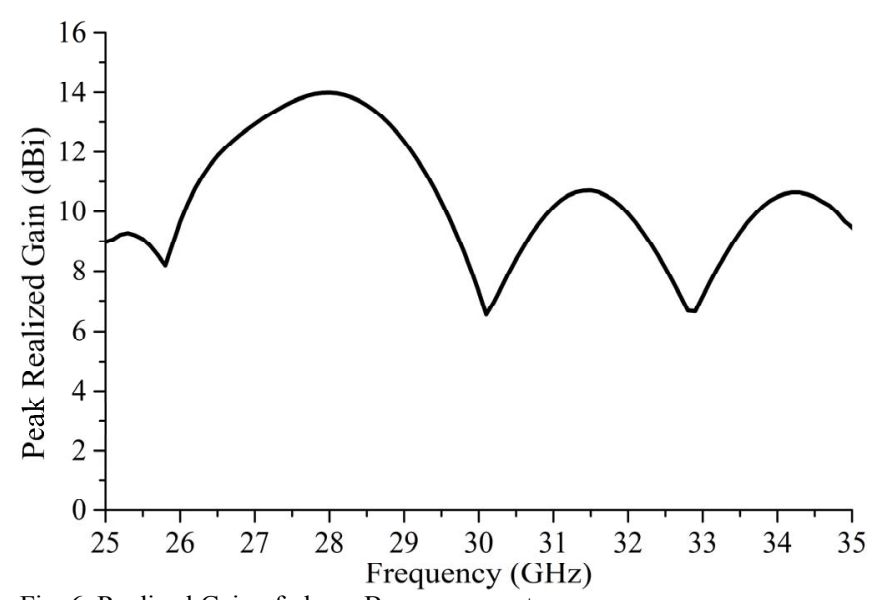

Fig. 6. Realized Gain of planar Bruce array antenna 


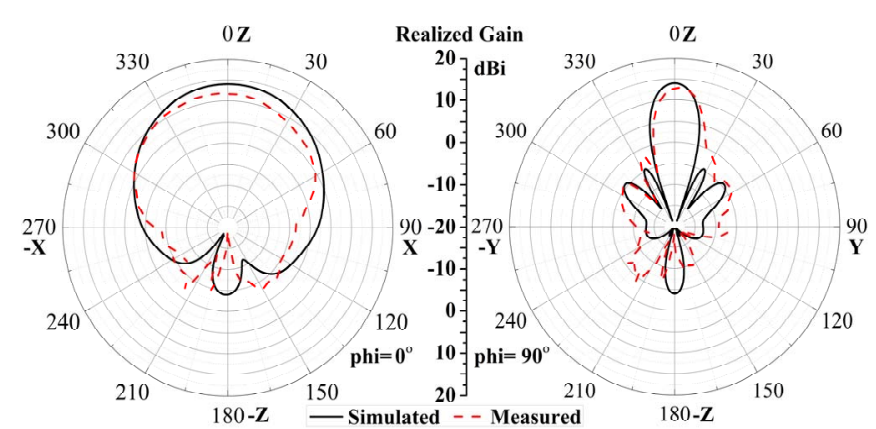

(a)

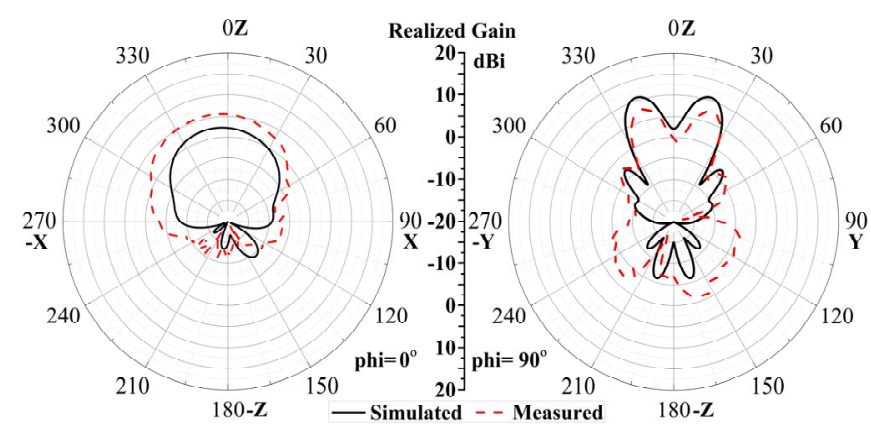

(b)

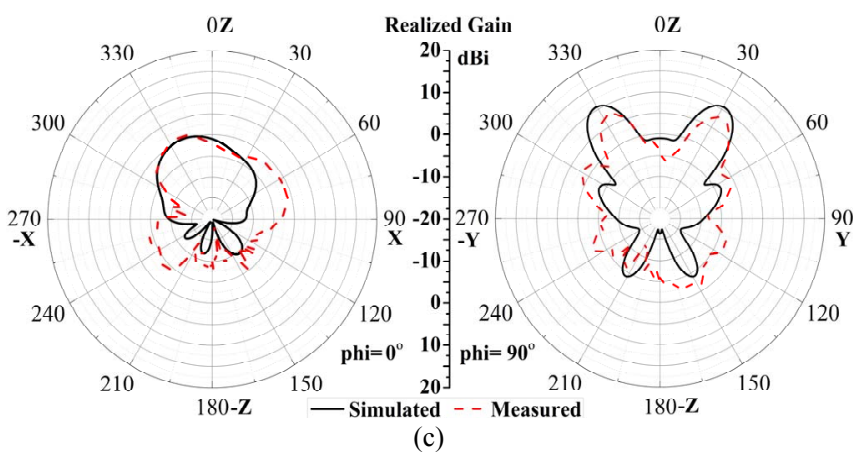

Fig. 7. Simulated and measured xz-plane and yz-plane radiation pattern plots at (a) $28.0 \mathrm{GHz}$ (b) $31.54 \mathrm{GHz}$ (c) $34.34 \mathrm{GHz}$

Figure 8 shows the surface current distribution plots. As discussed in the wire Bruce array antenna theory in section 2, the vertical elements add in phase to give rise to radiation. The radiating vertical elements, at $28.0 \mathrm{GHz}$ in Figure $8(\mathrm{a})$, have high distribution of current than the horizontal elements. This explains the highly directive radiation pattern shown in Figure 6. Figures 8(b) and 8(c) show the current distribution at $31.54 \mathrm{GHz}$ and $34.34 \mathrm{GHz}$, respectively. It can be seen from these figures that the currents are equally distributed in vertical and horizontal elements, of which, the latter behaved as interconnecting elements at $28.0 \mathrm{GHz}$. Since the antenna is fed from centre, the currents travelling in opposite direction are giving rise to dual beams in either direction as shown in Figures 7(b) and 7(c).

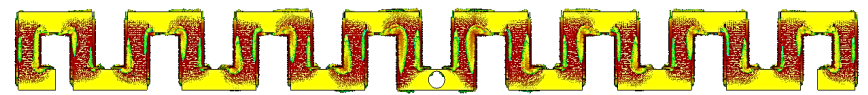

(a)

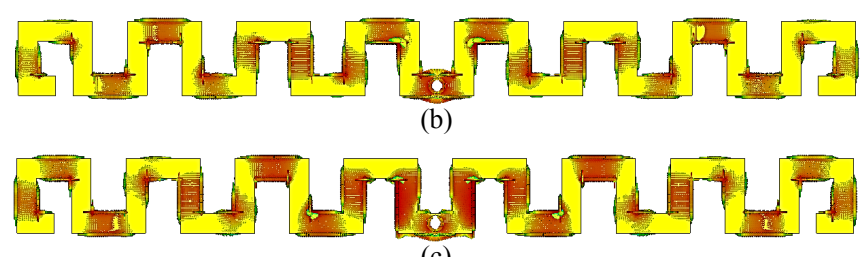

(c)

Fig. 8. Surface current distribution (a) $28.0 \mathrm{GHz}$ (b) $31.54 \mathrm{GHz}$ (c) $34.34 \mathrm{GHz}$

\section{CONCLUSIONS}

A compact, tri-band, 16-element planar Bruce array antenna of dimension $35.0 \times 9.0 \times 0.254 \mathrm{~mm}^{3}$ for $5 \mathrm{G}$, with peak gain of $14.0 \mathrm{dBi}$ at $28.0 \mathrm{GHz}$, is presented. The analysis of the antenna is performed with rear coaxial feeding arrangement with a full ground plane. The antenna has a broadside fan beam radiation pattern at $28.0 \mathrm{GHz}$, split beam radiation patterns at $31.50 \mathrm{GHz}$, with $34^{\circ}$ beam separation, and at $34.30 \mathrm{GHz}$ with $62^{\circ}$ beam separation.

\section{REFERENCES}

[1] E. Bruce, “Aerial System,” U.S. 1813143, Jul. 7, 1931.

[2] H. Nakano, N. Odachi, H. Mimaki and J. Yamauchi, "An array of Franklin and Bruce antennas," IEEE Antennas and Propagation Society International Symposium. 1996 Digest, Baltimore, MD, USA, 1996, pp. 1130-1133 vol.2.

[3] S. Chen, "Broadband Slot-Type Bruce Array Fed by a Microstrip-toSlotline T-Junction," in IEEE Antennas and Wireless Propagation Letters, vol. 8, pp. 116-119, 2009.

[4] Z. Ahmed, K. Yang, P. McEvoy and M. J. Ammann, "Study of mmWave microstrip patch array on curved substrate," Loughborough Antennas \& Propagation Conference (LAPC 2017), Loughborough, 2017, pp. 1-4.

[5] N. Ashraf, O. Haraz, M. A. Ashraf and S. Alshebeili, "28/38-GHz dual-band millimeter wave SIW array antenna with EBG structures for 5G applications," 2015 International Conference on Information and Communication Technology Research (ICTRC), Abu Dhabi, 2015 , pp. 5-8.

[6] M. Stanley et al., "A Dual-Band Dual-Polarised Stacked Patch Antenna for $28 \mathrm{GHz}$ and $39 \mathrm{GHz} 5 \mathrm{G}$ Millimetre-Wave Communication," 2019 13th European Conference on Antennas and Propagation (EuCAP), Krakow, Poland, 2019, pp. 1-4.

[7] Z. Ahmed, P. McEvoy and M. J. Ammann, "Comparison of Grid Array and Microstrip Patch Array Antennas at $28 \mathrm{GHz}, " 2018$ IEEE MTT-S International Microwave Workshop Series on 5G Hardware and System Technologies (IMWS-5G), Dublin, 2018, pp. 1-3.

[8] M. Steer, Microwave and RF Engineering: A Systems Approach. Raleigh, NC, USA: Scitech Publishing Inc., 2010. 